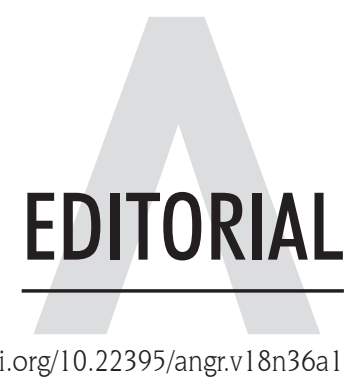

https://doi.org/10.22395/angr.v18n36al

\title{
El reto de los investigadores en comunicación
}

Un nuevo paradigma le depara a la comunidad científica de la revista Anagramas Rumbos y Sentidos de la Comunicación, las nuevas tendencias de la agenda setting hacen que las líneas de trabajo académico en el ámbito de la comunicación se encuentren alineadas con los propósitos de las regiones. Esto quiere decir que el nuevo reto de los investigadores tiene un alto contenido social que involucra las tecnologías como hilo conductor de los diálogos.

Lo primero que hay que decir es que conforme a la tendencia mundial de enfatizar la cultura a través de las industrias creativas y otorgarles el valor que merecen, así como subrayar la importancia que tienen en la vida de los ciudadanos, la revista Anagramas se encuentra adelantando discusiones para alcanzar la meta de convertir este escenario científico en una pantalla en la cual se expongan resultados de investigación de cultura y creatividad. El énfasis en las industrias culturales y creativas puede brindar oportunidades para un desarrollo económico que se base en los conocimientos, una sociedad con alta calidad de vida y altos estándares culturales, artísticos y creativos.

Es evidente que las reflexiones en torno a las industrias culturales son una prioridad para los gobiernos, un resultado de ello es que varias organizaciones han llegado a algunas conclusiones interesantes, por ejemplo, el Foro Económico Mundial expuso en diferentes escenarios académicos que el $60 \%$ de los trabajos actuales tendrán una nueva reclasificación y estructura. Basado en eso, los nuevos diseños de los puestos de trabajo adoptarán tres requerimientos: la resolución de problemas complejos, el pensamiento crítico y la creatividad. El Banco Interamericano de Desarrollo (BID) tuvo la oportunidad de reflexionar en torno a la "economía naranja", sus reflexiones han generado informes que afirman el valor de la creatividad y la cultura como enlace transversal de desarrollo en la región. Otra de las conclusiones que expone el BID es que las innovaciones nacidas de las industrias culturales y creativas pueden mejorar la productividad de sectores como el comercio minorista, la educación, el transporte 
o el turismo. Por otro lado, la Unesco propició la Convención sobre la Protección y Promoción de la Diversidad de las Expresiones Culturales en la Conferencia General de la Organización de las Naciones Unidas para la Educación, la Ciencia y la Cultura, en su $33^{\circ}$ reunión, celebrada en París del 3 al 21 de octubre de 2005. La Convención busca aglutinar investigadores de diferentes áreas que posibiliten el diseño y la implementación de políticas y medidas que apoyan la creación, producción, distribución y acceso a bienes orientados a las industrias creativas. La Convención tiene un propósito claro: el apoyo a los gobiernos y a la sociedad civil en la búsqueda de soluciones políticas para los desafíos emergentes.

Otro aspecto que se resalta en esta reflexión es que la comunicación digital y los procesos creativos han abierto la posibilidad a investigar nuevos objetos de estudio, el tema de investigar los medios tradicionales son una idea controvertida. Dichos objetos son, sin duda, una amalgama de experiencias que difícilmente se podrían acotar en un solo sentido y menos aún, en una sola disciplina. Con este, son dos los escenarios en los que las nuevas perspectivas de los investigadores en comunicación se deben acoplar para abrir un nuevo debate, pues para nadie es un secreto que hay múltiples críticas a este campo del saber.

La pregunta y los retos están planteados en la agenda de los investigadores, en otras palabras, el andamiaje de la investigación sobre la comunicación debe buscar de qué manera el buen uso de las industrias creativas puede crear espacios de intercambio de experiencias y cooperación en las regiones del país, esto es, alternativas de trabajo en la región bajo dinámicas de cooperación y complementariedad; un buen uso de esas industrias culturales puede crear un marco propicio para acelerar el conocimiento y la aplicación de los Derechos Humanos. La relación entre comunicación y democracia es esencial como tema de investigación, ya que los ciudadanos no solo requieren de información para la toma de decisiones, sino también para instaurar mecanismos de diálogo, participación y acción social basados en la industria creativa como motor de arranque para la estructuración de procesos democráticos.

Con esta reflexión presentamos la edición número 36 de la revista y con ella, una noticia que puede mejorar los procesos de circulación de nuestros trabajos, a partir de la edición 37, la revista Anagramas Rumbos y Sentidos de la Comunicación iniciará el proceso de publicación continua, esperamos que esta decisión aporte a una mayor circulación de los manuscritos.

Mauricio Andrés Álvarez Moreno Editor general 